\title{
Quantitative determination of rice cultivated areas using geospatial techniques
}

\author{
Ranu Rani Sethi ${ }^{1}$, Amiya Sagar Sahu ${ }^{1}$, M.J.Kaledhonkar ${ }^{2}$, A. Sarangi ${ }^{3}$, \\ Priyanka Rani ${ }^{1}$, Ashwani Kumar ${ }^{1}$ and K.G. Mandal ${ }^{1}$ \\ ${ }^{1}$ Directorate of Water Management, Bhubaneswar, Odisha \\ ${ }^{2}$ National Institute of Abiotic Stress Management, Baramati, Maharashtra \\ ${ }^{3}$ Water Technology Centre, IARI, New Delhi
}

\begin{abstract}
Spatial variability of crop coverage and delineation of cropped area not only assist in yield estimation but also provides information of crop water demand at regional scales. Such activity when accomplished using remote sensing image analysis techniques becomes less cumbersome and time consuming as compared to field survey. Present study was undertaken to delineate the rice cropped area in Haryana using the remote sensing image of 2000. Haryana is located under agro-climatic region VI with more than $70 \%$ of the population rely on agriculture for their livelihood. Arc GIS tool was used to classify the area under rice crop using Iso cluster unsupervised classification technique. It was accomplished by using the crop cover map besides the published reports to corroborate the findings. The total cultivated land was found to be 3526 thousand hectares in the year 2000 by the Planning Commission report, 2009. The total area under rice crop was found to be 1049 thousand hectares in the year 2000 by Agricultural Statistics at a Glance, 2001, Department of Agriculture, Haryana. However, the delineated area for the year 2000 using remote sensing was 1051 thousand hectares. However, such analysis with ground truthing information would be less cumbersome and accomplished with minimal cost and time. The protocol developed in this study pertaining to analysis of remote sensing image to delineate the cropped area can be replicated to other regions.
\end{abstract}

Keywords: Delineation, GIS, Remote Sensing, Satellite Image, Unsupervised classification.

\section{Introduction}

Remote sensing has been emerged as one of the cost effective and time saving technology in many fields of Science. It has been matured and become operational for natural resources survey, monitoring and management (Joseph G., 2003).Specially in the field of agriculture, it is being implemented to identify the location specific features for further interventions. Identification of different crop coverage is a very important technique, which provides vital information regarding the type and extent of crop cultivated in a particular area. This information has immense potential in the planning for further cultivation activities and for optimal land use planning (Omkar et al, 2009). Many studies have been carried out to develop the land cover classification in this regard.

All of the classification methods give varying results that depend on factors such as the type of satellite data and the subject of the classification. Factors such as the selected spectral bands, ancillary data, and the nature of the study area also affect the classification performance. Users about to undertake satellite data landcover classification should therefore be aware that their choice of data, class, and classification method will greatly influence the result (Foody and Arora, 1997). Abundant research has tested numerous algorithms for land cover classification and compared the results, focusing on specific cases (Friedle and Brodley, 1997; Anderson, et al., 1976). Unfortunately, these studies have tended to give fragmentary information, from the point of view that they do not offer guidelines for general users regarding which classification scheme is optimal for given data and class conditions. As the increasing availability of satellite data makes their utilization more popular, guidelines have become necessary for the selection of the correct and optimal data and a corresponding classification scheme.

Unsupervised classification is based on the exploitation of the inherent tendency of different classes to form separate spectral clusters in the feature space. Unsupervised classification uses algorithms that search for natural groupings of the spectral properties of the pixels. The computer selects the class means and covariance matrix to be used in the classification. Once the data is classified into clusters each clusters is then associated with a physical category (B.L. Deekshatulu and George Joseph, 1991). The object-oriented classification method was proved effective for separating vegetation types defined by life form, area, or shape without using additional remote-sensing data sources with different resolutions or any ancillary data such as digital elevation models ( $\mathrm{Li}$ and Shao, 2013). Considering the consistent relationship between the crop nutrients, wheat yield and the wheat spectral parameters, satellite remote sensing shows promise as a tool for assessing the variation in soil 
properties and yield in arable fields. The results suggest that management zone delineation using RS (Remote Sensing) data was reliable and feasible (Xiaoyu et al, 2009). Recent satellite sensors (e.g., Resourcesat-1, Cartosat-2, IKONOS-II, and RISAT-2), along with improved image processing techniques integrated with terrain and other spatial data using a geographic information system, are enabling mapping at large scale (Singh et al, 2010). Studies also revealed that using remote sensing data along with field survey and laboratory analysis for assessing the potentials and limitations of soil. Using the basic information on soil, climate and topography based on the matching exercise between the growth and production requirements of the crop, suitability of soils for groundnut, paddy and finger millet was assessed as per FAO (Food and Agricultural Organization) land evaluation. The soil suitability maps have also been prepared by using Arc GIS software (Sathish and Niranjana, 2010).

Agricultural area diversification plan has been generated from agricultural area and crop rotation maps derived from remote sensing data (IRS P6-AWiFS and RADARSAT Scan SAR) along with few agro-physical parameters in GIS environment (Choudhury et al, 2013). Semi-automated methodology for mapping cropland areas in the state of Mato Grosso, Brazil was developed by a Fourier transform over a time series of vegetation index products from the moderate resolution imaging spectroradiometer (Modis) sensor (Victoria et al, 2012). Implementation of image processing methodologies based on per-pixel methods for crop-shelter classification applied to high resolution multi-spectral satellite images were analyzed and discussed. The spectral information contained into these images was analyzed and mapped through indices. The results showed that improvements of crop-shelter classification could be achieved by using this information in comparison to RGB spectral information (Arcidiacono and Porto, 2012).

Although advanced remote sensing and GIS technologies have emerged to classify the crop land; but with view to lessen the time and at the same time to get the productive result it is expected to develop and adopt the simple processes so as to meet the desired result with the availability of minimum data sources. Present paper deals with developing the simple methodology to delineate the kharif rice area for the State of Haryana by using the satellite images for further interventions.

\section{Study area}

In the present study, rice area in Haryana State of India was delineated by remote sensing analysis. The area comes under the agro-climatic region VI, which lies within the geographical coordinates from $74.467936^{\circ}$ to $77.607357^{\circ}$ East longitude and $27.624316^{\circ}$ to $30.891281^{\circ}$ North latitude. Total geographical area is 44222 Sq.km (1.37\% of country's geographical area) with a population of 23 million (1.97\% of India's Population). More than $70 \%$ of the population of Haryana is dependent on agricultural sector for their livelihood. Major agricultural crops of the area are Wheat, Rice, Cotton, Oil Seeds, Guar, Bajra and Sugarcane etc.

\section{Materials and Method}

For delineating the rice area in the Haryana State, the website http://glcf.umd.edu was browsed and used for the image products. The detail of input remote sensing data for analysis is given in table no.1.

Table 1: The detail of input data

\begin{tabular}{|l|l|l|}
\hline \multicolumn{2}{|c|}{$\begin{array}{l}\text { Input Data } \\
\text { (Source: http://glcf.umd.edu) }\end{array}$} & $\begin{array}{l}\text { Software used for } \\
\text { Analysis }\end{array}$ \\
\hline Satellite & Landsat 7 & \multirow{2}{*}{ ArcGIS 10.0 } \\
\hline Sensor & ETM+ & \\
\hline Acquisition Date & September and October 2000 & \\
\cline { 1 - 1 } $\begin{array}{l}\text { Total no. of Images to } \\
\text { cover the entire State } \\
\text { of Haryana }\end{array}$ & 7 & \\
\hline
\end{tabular}

Images from ETM+ (Enhanced Thematic Mapper+) of Landsat 7 were of desired bands and resolution. The satellite images ( 5 No.) for the year 2000 were acquired for state of Haryana. These images covered most of the area of the Haryana except Faridabad and Palwal. As the images of year 2000 were not available for these two districts, two images for the year 1999 were used to complete the coverage of whole state. Every single image/scene of having unique path/row values comprises up of nine discrete bands such as: 1,2,3,4,5,6,6,7,8 that envisages nine different black and white images again. Hence for the entire coverage of the area, 63 remotely sensed images were acquired (2Nos. and 5 Nos. are in the year 1999, 2000 respectively). So, total 7 Nos. Images (each one is composed of nine discrete bands of black and white colour) were available to cover the Entire State. Thereafter the images were processed into Geographic Information System (GIS) for analysis. ArcGIS 10.0 GIS software enabled system was used to process acquired images. All the images were priorly 
geo-referenced in Universal Transverse Mercator (UTM_43z) projection system. To delineate areas under rice in the state, GIS based analysis methodology was developed.

Initially nine non-coloured images of different bands for the single scene were overlaid and transformed into a single raster composite using "Methods of Composite Bands" option of Data Management menu. The similar procedure was applied for other scenes. Finally seven composite rasters were developed. Then every image was portrayed by matching the edges of them in order to balance the overlap, also observing the pattern as well to get serially overlaid images. It helped in getting a mosaic raster out of seven composite raster. The composite rasters were further processed by "Mosaic to New Raster" option of Data Management Menu. The mosaic output contained the Haryana State and surrounding area. The area of the state was carved out by executing "Method of Extraction by Mask option" in Spatial Analyst extension for clipping the mosaic output. The Iso-cluster unsupervised classification was applied to clipped raster. District boundaries for Haryana state were overlaid on classified raster of the entire state so as to get classified mosaic output of individual district using "Method of Extraction by Mask option" in Spatial Analyst extension. The RGB channel of the extracted output raster was assigned with bands 4 (Near Infra Red), 3 (Red) and 2 (Green), respectively, to get False Colour Composite (FCC) so as to get maximum vegetation index reflectance for viewing crop area effectively. The entire classified extracted raster for the state and districts had a similar land use pattern (i.e. agriculture) predominantly covered by crops on the date of acquisition of data. Unsupervised classification was carried out for the analysis. However, district wise rice areas reported by Agricultural Statistics at a Glance, 2001, Department of Agriculture, Haryana for year 2000 were used as ground truths for comparing the results of unsupervised classification. The objective of analysis was to get the area under rice crop. Isocluster unsupervised classification of multivariate option of spatial analyst extension was followed to delineate rice area. In the classified raster image the attribute contained count values for different entity of the image in form of different classes. The count values represented number of pixels. Each pixel was of Spatial resolution of $(60 \times 60) \mathrm{m}^{2}=3600 \mathrm{~m}^{2}$. Multiplying the count values by the pixel resolution, the area under class was delineated.

Area under a particular feature class $=\mathrm{X} \times \mathrm{Y}$

Where $\mathrm{X}=$ Count Values as no. of pixels; $\mathrm{Y}=$ pixel resolution in $\mathrm{m}^{2}$ (Here, $3600 \mathrm{~m}^{2}$ since in ETM+ sensor, the pixel resolution is $60 \mathrm{~m} \times 60 \mathrm{~m}$ )

\section{Results and Discussion}

Initially on trial and error basis, image was classified for obtaining the rice distribution pattern from the satellite image. While selecting five (5) distinct feature classes for the unsupervised classification, the pattern was found out to be perfectly matching with the referenced distribution map of the study area. During the kharif season, maximum rice coverage area was observed for the entire State. Then further analyses were carried out to compare its exact area under rice cultivation. Its area was compared with the published report of Agricultural Statistics at a Glance, 2001, Department of Agriculture, Haryana. It was found that there was good co relation among the data obtained by remote sensing analysis and the published information. Then analysis was carried out for the individual districts of Haryana. The final map representing the rice area for the Haryana is shown in Fig.1.

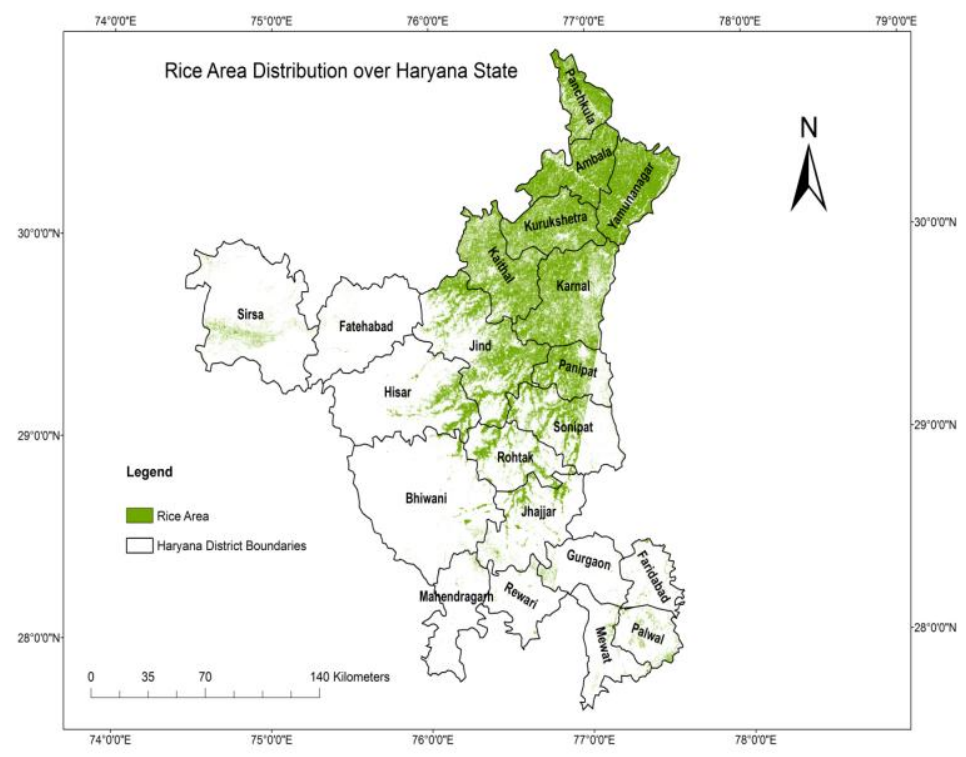

Fig.1: Spatial distribution of rice area in state of Haryana during year 2000 (Satellite Image Analysis) 
It shows the distribution of rice area in the state, which is dominated in north east Haryana and extends up to parts of central Haryana. The area under rice was limited in southern and south western Haryana. Out of the 21 districts of Haryana nine districts such as Panchkula, Ambala, Yamunanagar, Kurukshetra, Kaithal, Karnal, Jind, Panipat and Sonipat are predominantly rice occupied in the kharif (July Beginning to Mid October) crop season due to sound soil moisture and water availability. Rice coverage is moderate in the four districts like Hisar, Jhajjar, Sirsa and Rohtak. However, the remaining districts like Bhiwani, Faridabad, Fatehabad, Gurgaon, Mahendragarh, Mewat, Palwal, and Rewari are water stressed mostly arid land because of the high water table depth and less irrigation water supply. The total area covered under rice was found to be $24 \%$ out of its entire geographical area.

Table 2 showed the comparison between the rice areas delineated by Remote Sensing analysis and published report by Agricultural Statistics at a Glance, 2001, Department of Agriculture, Haryana. The total area estimated by remote sensing analysis was in agreement with published information. The total area under rice crop was found to be 1049 thousand hectares in the year 2000 by Agricultural Statistics at a Glance, 2001, Department of Agriculture, Haryana. From the remote sensing analysis the area was delineated as 1051 thousand ha which is at par with the referred values. However, there were variations in areas of individual districts.

Table 2: District wise rice area in state of Haryana

\begin{tabular}{|c|c|c|c|}
\hline Districts & $\begin{array}{l}\text { Count Values for } \\
\text { Rice in the } \\
\text { Classified images } \\
(\mathbf{X})\end{array}$ & $\begin{array}{l}\text { Area Estimate by Remote sensing } \\
\text { Analysis (XY) in ' } 000 \text { ha, } \\
\text { Where } X=\text { Count Value, } Y=3600 \mathrm{~m}^{2}\end{array}$ & $\begin{array}{l}\text { Area by Govt. of } \\
\text { Haryana } \\
\text { In ' } 000 \text { ha }\end{array}$ \\
\hline Ambala & 311829 & 112.25844 & 72.000 \\
\hline Bhiwani & 25350 & 9.126 & 8.000 \\
\hline Faridabad & 8818 & 3.17448 & 29.000 \\
\hline Fatehabad & 3131 & 1.12716 & 61.000 \\
\hline Gurgaon & 8004 & 2.88144 & 8.000 \\
\hline Hisar & 94573 & 34.04628 & 33.000 \\
\hline Jhajjar & 59737 & 21.50532 & 16.000 \\
\hline Jind & 354022 & 127.44792 & 112.000 \\
\hline Kaithal & 336121 & 121.00356 & 164.000 \\
\hline Karnal & 414814 & 149.33304 & 158.000 \\
\hline Kurukshetra & 292869 & 105.43284 & 112.000 \\
\hline Mahendragarh & 5299 & 1.90764 & 0 \\
\hline Mewat & 8350 & 3.006 & 0 \\
\hline Palwal & 22110 & 7.9596 & 0 \\
\hline Panchkula & 176913 & 63.68868 & 5.000 \\
\hline Panipat & 153415 & 55.2294 & 73.000 \\
\hline Rewari & 4629 & 1.66644 & 1.000 \\
\hline Rohtak & 86298 & 31.06728 & 24.000 \\
\hline Sirsa & 39255 & 14.1318 & 40.000 \\
\hline Sonipat & 145116 & 52.24176 & 77.000 \\
\hline Yamunanagar & 368814 & 132.77304 & 56.000 \\
\hline & Total & 1051.00812 & 1049.000 \\
\hline
\end{tabular}

Statistical comparison (Fig 2.) between estimates by Govt. of Haryana as observed values and satellite image analysis as simulated values showed good correlation coefficient with $\mathrm{r}^{2}=0.674$, which is within the permissible limit for accepting the classification. This showed that the methodology used for classifying the image can be used for other regions with limited data source. 


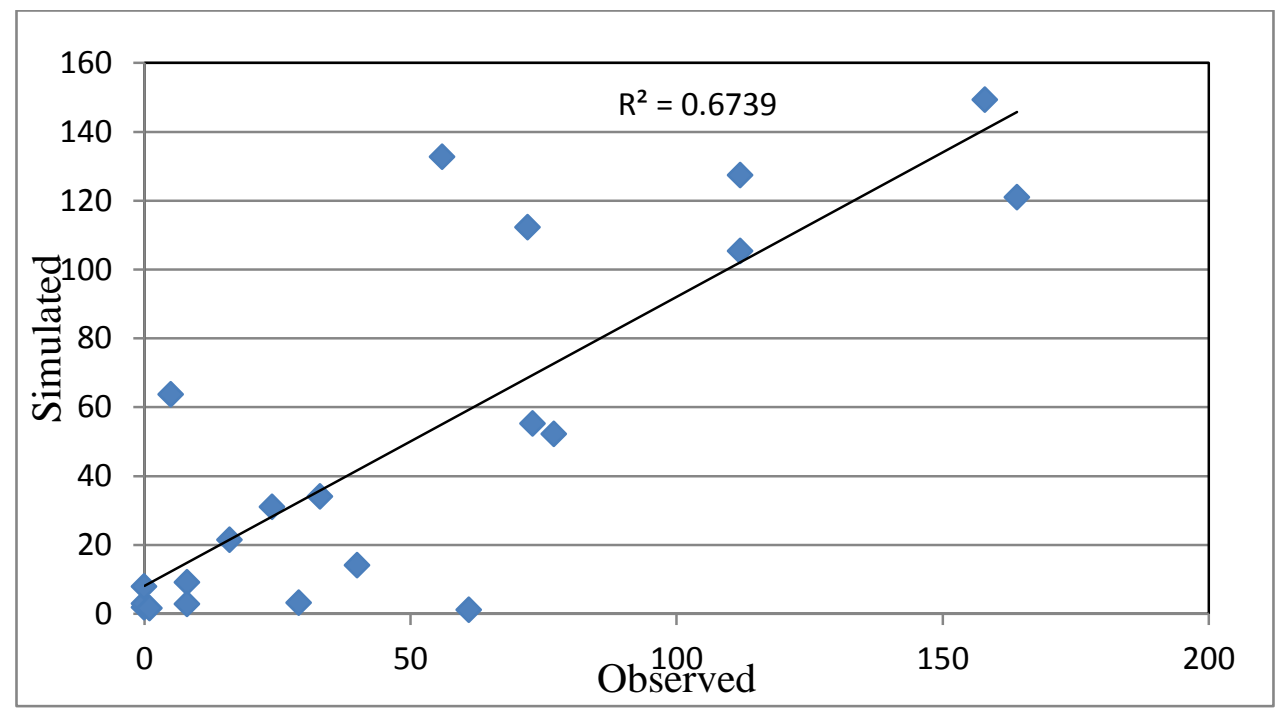

Fig 2: Statistical Comparison between estimates by Govt. of Haryana as observed values and remote sensing analysis as simulated values

\section{Conclusion}

In the present study, Landsat ETM+ satellite image was taken for delineation and estimation of rice crop areas in the state of Haryana,India. Remote sensing methodology was carried out for the satellite image in Arc GIS environment. Iso cluster unsupervised classification method was employed to classify the image and to delineate the rice area coverage. Areas covered under rice were well estimated by this process. The distribution pattern in the satellite image analysis could come out very clearly which matched with the maps prepared by government departments. Satellite images were acquired in the month of growing period (September and October). It influenced the remote sensing analyst that a broader area having crops in its peak growth stage could effectively be classified to quantify its coverage and to show its pattern of distribution. As a result the decision makers can figure out the measures to enhance the crop productivity and for other agricultural applications.

\section{Acknowledgement}

The authors would like to thank to all the involved staffs for providing their valuable efforts and time in undertaking this research work.

\section{References}

[1]. Agricultural Statistics at a Glance, 2001, Department of Agriculture, Haryana, P.30.

[2]. Anderson, J. R., E. E. Hardy, J. T. Roach, and R. E.Witmer. 1976. A land use and land cover classification system for use with remote sensor data. U. S. Geological Survey Professional Paper 964.

[3]. Arcidiacono, C. And Porto, S.M.C (2012) Pixel-Based Classification of High-Resolution Satellite Images for Crop-Shelter Coverage Recognition. Acta Horticulturae No.: 937, September 2012.

[4]. Choudhury, B.U., Sood, Anil Sood, Ray, S. S., Sharma, P.K. and Panigrahy, S. (2013). Agricultural Area Diversification and Crop Water Demand Analysis: A Remote Sensing and GIS Approach. Journal of the Indian Society of Remote Sensing Vol.: 41, No.: 1, March 2013, pp. 71-82.

[5]. Deekshatulu, B.L and Joseph 2, G (1991). Science of Remote Sensing. Current Science, Vol. 61, Nos. 3 \& 4.

[6]. Economic Survey of Haryana 2010-2011, Publication No.977, p.26

[7]. Foody, G. M. and Arora, M. K. (1997). An evaluation of some factors affecting the accuracy of classification by an artificial neural network. International Journal of Remote Sensing, Vol. 18, pp.799-810.

[8]. Friedle, M. A. and Brodley, C. E. (1997). Decision tree classification of land cover from remotely sensed data. Remote Sensing and Environment, Vol. 61, No. 3, pp. 399-409.

[9]. Joseph, G. (2003). Fundamentals of Remote Sensing. Current Science, Vol. 85, No. 10.

[10]. Li, Xiaoxiao and Shao, Guofan Shao. (2013) Object-Based Urban Vegetation Mapping with High-Resolution Aerial Photography as a Single Data Source. International Journal of Remote Sensing. Vol.: 34, No. 3, pp. 771-789.

[11]. Omkar, S. N., Senthilnath, J., Dheevatsa Mudigere and Manoj Kumar, M. 2008. Crop classification using biologically-inspired Techniques with High Resolution Satellite Image, Journal of the Indian Society of Remote Sensing, Vol.36, No. 2, June 2008, pp. 175-182.

[12]. Sathish, A. And Niranjana, K.V (2010) Land Suitability Studies for Major Crops in Pavagada Taluk, Karnataka Using Remote Sensing and GIS Techniques. Journal of the Indian Society of Remote Sensing Vol. 38, No. 1, March 2010, Page 143-151.

[13]. Singh, Gurbachan, Bundela, D.S.,Sethi, Madhurama Sethi, Lal, Khajanchi and Kamra, S. K.(2010). Remote Sensing and Geographic Information System for Appraisal of Salt-Affected Soils in India. Journal of Environmental Quality Vol. 39, No.: 1, February 2010, pp. 5-15. 
[14]. Song, Xiaoyu, Wang, J., Huang Wenjiang, Liu, Liangyun, Yan, Guangjian Yan and Pu, Ruiliang. 2009. The Delineation of Agricultural Management Zones with High Resolution Remotely Sensed Data. Precision Agriculture. Vol.10, No.6, December 2009, pp 471-487.

[15]. Victoria, Daniel De Castro; Paz, Adriano Rolim Da; Coutinho, Alexandre Camargo; Kastens, Jude; Brown, J. Christopher (2012). Cropland area estimates using Modis NDVI Time Series in the State of Mato Grosso, Brazil. Pesquisa Agropecuária Brasileira Vol.: 47, No.: 9, September 2012, pp. 1270-1278.

[16]. Websites: http://glcf.umd.edu, http://agriharyana.nic.in/AMapKharif.htm and www.esaharyana.gov.in. 